\title{
A municipalização da vacinação em Ribeirão Preto, Estado de São Paulo, Brasil 1
}

\author{
Municipalization of vaccination in Ribeirão Preto, \\ São Paulo, Brazil 1
}

Maria de Lourdes Gonçal ves 2

Maria Cecília Puntel de Almeida 3

Suelí Canhoto Gera 4

\footnotetext{
1 Artigo baseado em dissertação de Mestrado apresentada pela primeira autora à Escola de Enfermagem de Ribeirão Preto, Universidade de São Paulo.

2 Direção Regional de Saúde de Ribeirão Preto.

Rua Benedicta Domingos 889/41, Ri bei rão Preto, SP 14095-050, Brasil.

3 Departamento MaternoInfantil e Saúde Pública, Escola de Enfermagem de Ribeirão Preto, Universidade de São Paulo. Av. Bandei rantes 3900, Ribei rão Preto, SP 14040-902, Brasil.

4 Programa deVacinação no Município de Ribeirão Preto. Rua Amador Bueno 795, Ribei rão Preto, SP 14070-070, Brasil.
}

Resumo O presente estudo teve como objetivo estudar a organização das atividades do programa de vacinação no Município de Ribeirão Preto, durante o processo de municipalização da saú de, anal isando as mudanças ocorridas e avaliando os resultados al cançados. Utilizou-se dos segui ntes procedimentos metodológi cos: levantamento, através de visitas de supervi são e apli cação de questionários a enfermei ros e vacinadores, de todas as salas de vacinas da rede básica municipal de saúde deste muni cípio; levantamento das condi ções de armazenamento dos imunobiológicos e insumos a nível municipal eaplicação de questionário com o responsável pelo setor; entrevistas com profissionais de saúde responsávei s pel a vaci nação, nos níveis estadual regional e municipal central. Concluiu-se que, desde a implantação das Ações I ntegradas de Saúde, houve uma expansão da rede bási ca municipal de saúde e também dos serviços de vacinação; houve também uma centrali zação técnico-admi ni strativa das deci sões que envolvem as atividades de vaci nação, inclusive o preparo dos recursos humanos, através do Grupo deVigilância Epidemiológi ca Municipal. Verificou-se ainda que, embora esta atividade venha sendo tratada com prioridade pelos responsáveis a nível municipal central e distrital, o mesmo ainda não ocorre no nível local.

Palavras-chave Vacinação; Serviços de Saúde; Atenção Primária em Saúde; Saúde Pública

Abstracts The object of this study is the organization of activities in the vaccination program in Ri bei rão Preto, São Paulo, during the process of municipalization of heal th services, analyzing changes and estimating results. The methodol ogy included a survey performed during supervisory visits and questionnaires with 20 nurses and 39 vaccination workers in all the vaccination rooms at the municipal primary health care unit in this city, a survey of storage conditions for immunobiological products at the municipal level and a questionnai re for the section head, and interviews with five health professionals responsible for vaccination at the State, regional, and municipal levels. It followed that since implementation of the so-called Integrated Health Actions proposal there has been an expansion of primary health care services, including vaccination services; there has also been a technical and administrative centralization of decisions involving vaccination activities, including training of human resources by the Municipal Epidemiological Surveillance division. The study points out that al though this activity is dealt with carefully by those responsiblefor the State, municipal, and district levels, the sameis not true at the local level. Key words Vaccination; Health Services; Primary Health Care; Public Health 


\section{Introdução}

A partir dos anos 70, como conseqüência da conjuntura econômica, política e social, ocorreram intensas mobilizações políticas e grandes mudanças no setor saúde brasileiro, as quais se deram paralelamente às propostas gestadas nos organismos internacionais (OMS/ OPS). O Brasil aderiu à proposta de extensão de cobertura dos serviços de saúde, definida na III Reunião de Ministros da Saúde das Américas, realizada no Chile, em 1972, com o PIASS - Programa de Interiorização das Ações e Serviços de Saúde, em 1974.

Em 1978, a Conferência Internacional sobre Cuidados Primários em Saúde, realizada em Alma Ata, enfatizou a necessidade de que os países em desenvolvimento, entre eles o Brasil, implementassem políticas de saúde capazes de melhorar os indicadores de morbi-mortalidade de seus povos, principalmente com ações de controle das doenças transmissíveis, entre elas, a vacinação. Para atender esta recomendação da OPS e também buscando uma forma de racionalizar o uso dos recursos do INAMPS, o governo brasileiro cria, em 1982, o Plano de Reorientação da Assistência à Saúde no âmbito da Previdência Social, do CONASP - Conselho Consultivo de Administração da Saúde e Previdência (MPAS, 1982). Este plano previa uma reorganização gradativa dos serviços de saúde, com vistas a criar um sistema descentralizado, hierarquizado, regionalizado e de acesso universal. A operacionalização do Plano do CONASP deu-se a partir das Ações Integradas de Saúde - AIS (MS, 1985), que previam a celebração de convênios entre o Ministé rio da Previdência e Assistência Social - MPAS, através do INAMPS, Ministério da Saúde e Secretarias de Estado da Saúde. Estes convênios começaram a ser assinados em 1983 e previam o repasse de recursos financeiros da União para os estados e destes para os municípios. Isso permitiu que a extensão de cobertura fosse viabilizada, principalmente através da expansão da rede física de Unidades de Saúde, em muitos municípios brasileiros. Em relação às ações previstas nas AIS, a atividade de vacinação é uma das que obtiveram, desde o início da extensão da rede, uma ampliação da oferta.

Em 1986, realizou-se, em Brasília, a VIII Conferência Nacional de Saúde (MS, 1987), a qual concluiu que a viabilização das AIS seria a estratégia para se conseguir a tão sonhada Reforma Sanitária brasileira, defendida por todos os presentes. Esta passou a ser uma possibilidade concreta a partir da Nova Constituição Federal de 1988 (Brasil, 1988), que incluiu o Direito à Saúde como um dos Direitos Cons- titucionais. Trouxe também a definição de um Sistema Único de Saúde, de âmbito nacional, com gestão descentralizada e hierarquizada.

Nesse mesmo período, o governo dava novos encaminhamentos para a criação de um Sistema Nacional de Saúde, com a implantação dos SUDS - Sistemas Unificados e Descentralizados de Saúde, em 1987, através de convênios. Esses convênios incluíam um Projeto de Municipalização da Saúde, e começaram a ser celebrados entre as Secretarias Estaduais de Saúde e os municípios, ainda em 1987, prevendo que a saúde deveria ser de responsabilidade do município.

O processo, iniciado na década de 70, culmina em 1990, com a criação do Sistema Único de Saúde - SUS, através da aprovação da Lei Orgânica da Saúde - LOS (Brasil, 1990) pelo Congresso Nacional, em setembro daquele ano. Ressalta-se que cada uma destas etapas, desde a criação do Plano do CONASP até a fase de Municipalização da Saúde, vem sendo viabilizada com muita polêmica, apresentando avanços e retrocessos e que a concretização do SUS vem enfrentando sérias dificuldades, principalmente no que se refere ao seu financiamento.

A preocupação com a vacinação sempre esteve presente nas propostas das políticas do setor de forma geral e, em particular, nas de atenção primária de saúde, apontando para aspectos de prevenção de doenças e/ ou proteção específica. É também a partir dos anos 70 que os organismos internacionais, como a OMS e OPS, começam a propor políticas específicas para a sistematização da vacinação em forma de programa, visando principalmente os países em desenvolvimento, motivados também pela erradicação da varíola no mundo, através de vacinação em massa contra esta doença.

Desta maneira, a OMS criou em 1974 o Programa Ampliado de Imunizações - PAI (OMS, 1974), com a finalidade de colocar à disposição das crianças de todo o mundo até o ano de 1990 as vacinas já disponíveis para o controle de doenças transmissíveis, como: a difteria, a coqueluche, o tétano, a paralisia infantil, a tuberculose e o sarampo. No Brasil, já eram desenvolvidas atividades sistematizadas de vacinação, ainda que localizadas, e já em 1973 é criado o Programa Nacional de Imunizações - PNI (MS, 1984), que mais tarde incorporou as diretrizes técnicas de atuação do PAI. A regulamentação deste programa foi feita a partir de 1975, com a Lei no 6259 (Brasil, 1975), que organiza as ações de vigilância epidemiológica e inclui a atividade de vacinação. O PNI integrou e ampliou as atividades de vacinação que já vinham sendo postas em prática por alguns estados, como São Paulo. A partir de então, as ações de vacinação desenvol- 
veram-se sob inteira responsabilidade do Ministério da Saúde e Secretarias Estaduais da Saúde, quanto à provisão, manutenção, normatização, até à operacionalização nos Centros de Saúde e Postos de Vacinação, seguindo as diretrizes técnicas do Programa Nacional de Imunização - PNI.

Com a adesão ao Convênio de Municipalização da Saúde, que em Ribeirão Preto - SP ocorreu em 27 de novembro de 1987 (Ribeirão Preto, 1987), as atividades de vacinação passaram a ser de responsabilidade técnica e operacional da Secretaria Municipal de Saúde. A descentralização administrativa e operacional teve como conseqüência uma ampliação das responsabilidades da Secretaria Municipal de Saúde, que até então apenas executava as normas pré-estabelecidas pelas instâncias estadual e federal. A partir da municipalização da saúde, outras ações que integram a Vacinação passaram também a ser desempenhadas pela Secretaria Municipal da Saúde, como: compra de equipamentos esua manutenção; distribuição dos imunobiológicos e insumos para a atividade de vacinação; orientação técnica, supervisão e controle da rede de frio; contratação e capacitação dos re cursos humanos envol vidos; credenciamento de novos Postos deVacinação, entre outras. Até a assinatura do Convênio AIS pelo Município de Ribeirão Preto, em 1983 (Ribeirão Preto, 1984), existiam 14 salas de vacinação em funcionamento nesta cidade, distribuídas nos bairros mais centrais. A subordinação administrativa destas era atribuída a cinco instituições, sendo duas federais, nove estaduais e três municipais.

Com a finalidade de conhecer a produção científica específica sobre os aspectos organizacionais e administrativos da vacinação, realizouse um levantamento bibliográfico sobre a temática, do período após 1975, quando o PAl foi implantado, nos periódicos Boletin de la Oficina Sanitária Panamericana; Catálogos de Teses do Centro de Pesquisas em Enfermagem - CEPEn; Revista de Saúde Pública; Revista Brasileira de Enfermagem e, também, no arquivo de teses de mestrado e doutorado do Departamento de Medicina Social da Faculdade de Medicina de Ribeirão Preto - USP. Encontraram-se oito trabalhos sobre a temática em estudo: Sobral (1978), Foster (1979), Almeida et al. (1980), Costa \& Almeida (1980), Begossi (1984), Christensen \& Karlqvist (1990), Etienne (1990), e Pinhata (1990). Os aspectos organizacionais foram abordados em três: Sobral (1978), Foster (1979) e Etienne (1990). Verifica-se também que, dos quatro estudos que tratavam da vacinação em Ribeirão Preto, apenas um abordou aspectos organizacionais.

O levantamento bibliográfico realizado permitiu verificar que são poucos os trabalhos que tratam da temática vacinação, nos seus aspectos organizacionais e operacionais de um programa, eque abranja um município como um todo.

Desta maneira, o objetivo deste trabalho foi analisar como se deu a organização técnicoadministrativa das atividades do Programa deVacinação Infantil no Município de Ribeirão Preto, durante o processo de Municipalização da Saúde, identificando e analisando as mudanças ocorridas e avaliando os resultados alcançados.

Tinha-se por pressuposto que a municipalização da vacinação propiciaria a descentralização administrativa, técnica e política com maior autonomia e maior extensão da oferta destes serviços e melhoria da qualidade.

\section{Metodologia}

Tendo em vista que o objeto de investigação era a organização das atividades do Programa de Vacinação no Município de Ribeirão Preto, realizou-se um estudo descritivo, contendo dados quantitativos e qualitativos em um corte transversal realizado em 1993. Para tal, utilizaram-se os seguintes procedimentos metodológicos:

a) Levantamento, através de visitas de supervisão, da situação organizacional e funcional dos vinte e dois serviços de vacinação da Rede Básica de Saúde de Ribeirão Preto, no ano de 1993, acrescido da aplicação de questionário com os profissionais envolvidos nesta atividade, sendo 20 enfermeiros e 39 vacinadores.

b) Levantamento das condições de armazenamento dos imunobiológicos e dos insumos a nível municipal, com aplicação de questionário com o responsável pelo setor e observação direta do local.

Os roteiros utilizados nos levantamentos e nos questionários foram elaborados com base nos Roteiros para Inspeção e Supervisão de Postos de Vacinas Credenciados, elaborados por técnicos do Centro deVigilância Epidemiológica "Alexandre Vranjac" da Secretaria Estadual de Saúde do Estado de São Paulo (São Paulo, 1989). Estes instrumentos permitiram levantar a situação organizacional e funcional das salas de vacinas, no que se refere aos equipamentos, aos recursos humanos disponíveis e às articulações do nível local com os outros níveis hierárquicos da rede municipal de saúde. Além disso, permitiram verificar e registrar a situação de como se encontrava organizado o serviço de vacinação, comparando-o com as normas preconizadas pelo Programa Nacional de Imunizações - PNI, e tendo como referência os seguintes indicadores: Normas de instalação e funcionamento de salas de vacinas; Controle da Rede 
de Frio; Armazenamento dos imunobiológicos e insumos; Registro dos dados; Preparo e supervisão dos recursos humanos em vacinação.

c) Entrevistas semi-estruturadas com os cinco profissionais responsáveis pelo setor de vacinação nos níveis centrais estadual, regional e municipal de saúde nos dois períodos em questão: 1987, quando teve início a descentralização, e em junho de 1993, ano do presente estudo, quando já estava implantada a municipalização da vacinação. As entrevistas tiveram a finalidade de obter informações sobre os possíveis benefícios alcançados com a descentralização da vacinação e também sobre as dificuldades vividas. A questão norteadora das entrevistas foi: “Como se deu a transferência das responsabili dades e competências da vacinação, do nível regional estadual para o municipal, facilidades e difi culdades encontradas".

\section{Resultados e discussão}

Condições de organização e funcionamento das salas de vacinas

Foram visitadas e observadas a totalidade das vinte e duas salas de vacinas do município de Ribeirão Preto, em funcionamento no período do levantamento, que foi de 17 de maio a 17 de junho de 1993. Os dados foram agrupados nos subitens a seguir:

- Vacinas aplicadas, horário de funcionamento, instalações físicas, insumos e armazenamento do material descartável

Nos serviços de vacinação são aplicadas todas as vacinas previstas no PNI. A maioria das Unidades (16) funciona das 7 às 17 horas. O horário de funcionamento das salas de vacinas encontra-se na Tabela 1.

Tabela 1

Horário de funcionamento das salas de vacinas da rede básica de saúde do Município de Rib. Preto, 1993.

\begin{tabular}{lcc}
\hline Horário & Dias da semana & Número de salas \\
\hline 7 às $17 \mathrm{~h}$ & dias úteis de 2a a $6^{\text {a }}$ feira & 09 \\
7 às $16 \mathrm{~h}$ & idem & 05 \\
7 às $16: 30 \mathrm{~h}$ & idem & 01 \\
7 às $17 \mathrm{~h} *$ & idem & 02 \\
7 às $22 \mathrm{~h}$ & idem & 01 \\
8 às $16 \mathrm{~h}$ & idem & 02 \\
8 às $17 \mathrm{~h}$ & idem & 01 \\
9 às $15 \mathrm{~h}$ & idem & 01 \\
\hline
\end{tabular}

* fecha durante $1 \mathrm{~h}$ para o almoço
Observa-se que o horário de funcionamento corresponde apenas aos dias úteis, dentro do horário comercial, não acompanhando todo o período de atendimento da Unidade. O simples fato de o horário da sala de vacinas não coincidir com o horário dos demais atendimentos, com certeza tem levado à ocorrência das oportunidades perdidas em vacinação, o que tem sido uma das principais preocupações do PAl no momento.

De modo geral, as instalações físicas estão de acordo com as normas preconizadas pela Secretaria Estadual de Saúde - SES, com exceção de seis salas que são divididas com outros atendimentos, dificultando a compreensão das orientações educativas que são realizadas junto ao acompanhante. Observou-se, em algumas salas, a falta de materiais imprescindíveis para a execução da vacinação, como: seringas e agulhas descartáveis para diluição, seringas descartáveis para aplicação do BCG-ID, folha para registro da temperatura do refrigerador, boletim de previsão mensal e boletim mensal de doses aplicadas. Como não havia falta de nenhum destes materiais a nível central, além dos possíveis problemas na distribuição, poderia estar ocorrendo também uma previsão inadequada pelas UBSs. Em todas as salas, o material descartável encontrava-se armazenado de maneira adequada.

- Manutenção e controle da rede de frio, armazenamento dos imunobiológicos e diluentes nas UBSs

Todas as salas de vacinas fazem o controle da temperatura dos refrigeradores, tanto de estoque quanto de uso diário, com o termômetro de máxima e mínima, apenas nos dias em que estão em funcionamento. Em todas elas, os termômetros foram lidos no momento da visita e todos apresentavam temperatura entre $+2^{\circ} \mathrm{C}$ e $+8^{\circ} \mathrm{C}$. Segundo as normas da SES, a verificação da temperatura no interior dos refrigeradores, tanto de estoque quanto de uso diário, deve ser feita diariamente e registrada. Observou-se que este procedimento só é realizado em quatro salas de vacinas, nas Unidades que funcionam diariamente. A disponibilidade de refrigeradores para conservação dos imunobiológicos, bem como sua utilização, pode ser vista na Tabela 2.

Ao analisar-se a Tabela 2, verifica-se que, em todas as salas de vacinas, nenhum dos refrigeradores é exclusivo para este fim. A conseqüência disto é que as oscilações de temperatura, principalmente acima do máximo permitido, são freqüentes, tendo em vista que estes refrigeradores são manipulados um maior nú- 
mero de vezes e por diferentes profissionais, os quais nem sempre têm conhecimento da termolabilidade das vacinas. Outro problema detectado é o fato de que, em cinco salas de vacinas, o refrigerador de uso diário e de estoque é o mesmo, fato este que também expõe os imunobiológicos a oscilações de temperatura que podem alterar sua eficácia.

- Armazenamento dos imunobiológicos e insumos no nível municipal

O armazenamento dos imunobiológicose insumos no nível central municipal pode ser considerado adequado, bem como a área física, localização e equipamentos disponíveis. O número de refrigeradores é suficiente, são exclusivos para os imunobiológicos e o estado de conservação dos mesmos corresponde ao desejado. Os resultados desta centralização são considerados satisfatórios, pois está havendo um controle diário da temperatura do estoque mensal dos imunobiológicos do município, o que nem sempre era possível quando as vacinas do estoque mensal municipal ficavam armazenadas em quatro Centros de Saúde, em refrigeradores, cujas temperaturas não eram verificadas diariamente.

- Registro das vacinas aplicadas e arquivo das fichas de registro

Todos os vacinadores pesquisados informaram que as doses aplicadas diariamente eram anotadas no mapa diário de doses aplicadas. Quanto ao arquivamento das fichas de registro, em 19 salas de vacinas, estas estavam arquivadas por faixa etária, por data de retorno (dia e mês) e, em separado, as dos faltosos. As demais salas (03) estavam com as fichas de registro arquivadas apenas em ordem alfabética, não estando separadas nem mesmo as de menores de um ano, grupo etário prioritário para o Programa de Vacinação.

O Programa Nacional de Imunizações implantou, a partir de 1977, um sistema de arquivo das fichas de registro, separando por faixa etária e por data de retorno (dia e mês), destacando-se os faltosos. O arquivo de vacinação permite avaliar a adesão ao programa, isto é, verificar quantas crianças iniciam e completam o esquema básico na mesma Unidade. Embora apenas três salas não atendam a esta recomendação, considera-se isto uma deficiência, tendo em vista a importância deste instrumento para o acompanhamento da vacinação.
Tabela 2

Presença de refrigeradores para conservação dos imunobiológicos no nível local.

\begin{tabular}{lll}
\hline Refrigerador & Sim & Não \\
\hline Estoque & $17^{*}$ & 05 \\
Uso diário & $21^{* *}$ & 01
\end{tabular}

* Não são de uso exclusivo para os imunobiológicos;

** Cinco destes são usados para guardar outros materiais.

\section{- Recursos Humanos}

Aqui foram discutidos os resultados dos questionários aplicados com os vacinadores e enfermeiros de nível local no que se refere à caracterização dos mesmos, ou seja, número, formação e preparo para executar a vacinação, bem como problemas apontados para a execução da vacinação.

\section{- Vacinadores}

Todos os vacinadores que no período das visitas estavam "escalados" para a sala de vacinas responderam ao questionário, totalizando 39. Levantou-se também, junto ao enfermeiro, quantos funcionários capacitados em vacinação poderiam ser escalados para esta atividade. O resultado pode ser verificado na Tabela 3.

Observa-se que a maioria das Unidades (14) conta com apenas um vacinador por período de atendimento e têm, 39\% do total de vacinadores disponíveis, enquanto que as demais Unidades (8) contam com dois ou mais vacinadores por período e têm, no total, $61 \%$ dos vacinadores disponíveis. Além disso, observa-se que apenas 39 (26\%) dos vacinadores disponíveis estavam escalados para a vacinação no período do levantamento. Verifica-se que seria possível uma distribuição mais adequada destes vacinadores disponíveis, dando

Tabela 3

Distribuição dos vacinadores escalados nas Unidades, segundo número por período de atendimento e total de disponíveis.

\begin{tabular}{|c|c|c|c|c|c|c|}
\hline \multirow{2}{*}{$\begin{array}{l}\text { Número } \\
\text { de unidades } \\
\text { por período }\end{array}$} & \multicolumn{2}{|c|}{ Unidades } & \multicolumn{2}{|c|}{$\begin{array}{c}\text { Vacinadores } \\
\text { escalados }\end{array}$} & \multicolumn{2}{|c|}{$\begin{array}{l}\text { Vacinadores } \\
\text { disponíveis }\end{array}$} \\
\hline & $\mathrm{n}$ & $\%$ & $n$ & $\%$ & $n$ & $\%$ \\
\hline $\begin{array}{l}1 \text { vacinador por } \\
\text { período }\end{array}$ & 14 & 64 & 16 & 41 & 58 & 39 \\
\hline $\begin{array}{l}2 \text { ou mais } \\
\text { vacinadores por } \\
\text { período }\end{array}$ & 08 & 36 & 23 & 59 & 90 & 61 \\
\hline Total & 22 & 100 & 39 & 100 & 148 & 100 \\
\hline
\end{tabular}


prioridade à sala de vacinas, no momento de se elaborar a escala mensal dos funcionários da Unidade, principalmente nos horários de maior demanda de algumas delas. O resultado do pequeno número de funcionários escalados acarreta demora no atendimento, provocando impaciência na clientela, principalmente nos horários de pico, e encaminhamento para outros horários e/ ou serviços, provocando perdas de oportunidade de vacinação.

Quanto à categoria profissional, observa-se que, dos vacinadores disponíveis, 125 são auxiliares de enfermagem; oito são técnicos em enfermagem; 10 são atendentes de enfermagem e cinco são visitadores sanitários. O tempo, em anos, de atividade profissional no setor de vacinação dos 39 vacinadores escalados é, em sua maioria (25), inferior a cinco anos. Fica evidente que os vacinadores escalados são bastante jovens nesta atividade e, conseqüentemente, com pouca experiência profissional. Torna-se necessário, portanto, uma supervisão constante dos mesmos, com a finalidade de aprimorar seus conhecimentos e sua prática no dia-a-dia.

Quanto ao tipo de treinamento que receberam para atuar em vacinação, nove dos vacinadores escalados foram treinados apenas em serviço; 17 receberam treinamento formal; 13 foram treinados nas duas modalidades: em serviço e formalmente.

Quanto aos problemas e dificuldades que os vacinadores encontram para desempenhar sua função, foram apontados os aspectos relativos a: clientela atendida, recursos humanos envolvidos e operacionalização da vacinação.

Os problemas relativos à clientela atendida serão analisados juntamente com as questões trazidas pelos enfermeiros. Em relação aos problemas com os recursos humanos, observaram-se muitas referências sobre o que foi agrupado como "má distribuição de responsabilidades", que incluem, entre outras queixas: "excesso de rodízio, ninguém se sente responsável pela sala e pela vacina, alguns são sobrecarregados, falta de coleguismo, injustiças, etc." Tais problemas são apontados talvez por falta de um trabalho com toda equipe visando a um esclarecimento sobre cada setor da Unidade, para possibilitar um maior entrosamento e articulação entre os diferentes setores e melhor compreensão das ações de saúde pública que devem ser desenvolvidas no nível local de atendimento. Há também muitas referências sobre falta de treinamentos e desvalorização das chefias pela atividade de vacinação. Apontaram também falta de treinamento e/ ou supervisão a nível local. Quanto à supervisão, observou-se que, embora toda UBS tenha pelo menos um enfermeiro por período de trabalho, nem sempre ele toma a atividade de vacinação como uma de suas responsabilidades, levando o vacinador a ter que se comunicar diretamente com o nível central.

\section{- Enfermeiros}

Das 22 Unidades, 20 enfermeiros responderam ao questionário, quando presentes por ocasião da visita dos pesquisadores; destes, nove ainda não haviam recebido treinamento em vacinação; dos que receberam (onze), seis haviam sido treinados formalmente (teoria e prática), três tiveram treinamento apenas prático e dois, apenas teórico. Quanto às atividades do enfermeiro na vacinação, dezoito referiram que "sempre", "a todo momento", "diariamente", entravam em contato com esta atividade. Em apenas uma Unidade o enfermeiro referiu fazer treinamento em serviço sobre vacinação para novos funcionários admitidos. Com relação à cadeia de frio, observou-se que 19 enfermeiros já vivenciaram situações de alteração de temperatura dos refrigeradores. Este foi um dos problemas verificados pelos pesquisadores etambém citados pelos vacinadores pesquisados. Quanto à supervisão que recebem de outros níveis, 14 disseram que são supervisionados a distância e seis não recebem supervisão. Foram citadas as circunstâncias nas quais ocorre a supervisão: "quando solicitam” (08); "quando têm problema" (05); "quando implantam novas vacinas" (04); "para treinamento" (03); "para fazer bloqueio de doenças transmissíveis" (01); e "devido à mudança do ProntoSocorro" (01).

A carência de treinamentos está presente na fala da totalidade dos enfermeiros pesquisados. Considerou-se preocupante este fato, tendo em vista a especificidade das atividades do Programa de Vacinação e a expectativa de que este profissional é quem deve responsabilizar-se, através de supervisão, por esta atividade. Esta expectativa é confirmada, quando verifica-se que dezoito dos vinte enfermei ros são solicitados diariamente pelos vacinadores para orientar e esclarecer dúvidas sobre vários aspectos da operacionalização da vacinação.

O fato de a Secretaria Municipal de Saúde ter assumido o preparo dos recursos humanos em vacinação, como uma das conseqüências da municipalização da saúde, é um ponto positivo. No entanto, espera-se que, quando os enfermeiros de nível local são capacitados, eles tenham autonomia para tomar decisões no seu dia-a-dia, visando a dar maior agilidade e resolutividade aos procedimentos sobre vacinação. Esta autonomia deveria incluir o treinamento 
dos vacinadores, bem como a tomada de decisões frente a algumas situações emergenciais, por exemplo, em relação aos problemas com a cadeia de frio, problemas estes muito freqüentes, conforme relatado anteriormente. $\mathrm{O}$ fato de os enfermeiros do nível local não se envolverem com o treinamento dos vacinadores dificulta a supervisão continuada dos mesmos.

- Valor atribuído à atividade de vacinação

Tanto os vacinadores quanto os enfermeiros referiram que os "outros setores da Unidade, como o atendimento em Pediatria, GinecoIogia e Obstetrícia e Clínica Médica, não valorizam a atividade de vacinação". Isto demonstra que as ações preventivas no nível primário de atenção não estão sendo privilegiadas na atual forma de organização dos serviços. O enfermeiro poderia ser o profissional motivador da equipe, possibilitando uma maior articulação entre os diferentes setores da Unidade, para que a vacinação fosse vista e pensada além dos limites da sala de vacinas, deixando de ser preocupação apenas do vacinador escalado. Poderia ser uma atividade lembrada e conduzida de maneira a viabilizar um trabalho de equipe, no qual as ações educativas e preventivas inerentes à vacinação fizessem parte do cotidiano de todos que trabalham na Unidade.

- Relacionamento com a clientela atendida

Os problemas e dificuldades no relacionamento com a clientela apontados pelos vacinadores e pelos enfermeiros podem ser observados na Tabela 4.

Observa-se, nesta Tabela, que os vacinadores, em sua maioria, referem muitos aspectos negativos em relação à clientela atendida. É preocupante este fato, pois demonstra que o relacionamento entre os vacinadores e a demanda de clientes não está se dando de maneira satisfatória para ambos. Há poucas referências aos aspectos positivos. O direito dos usuários à assistência de qualidade ainda não é possibilitado, nem mesmo nas atividades de vacinação.

Quanto aos enfermeiros, verifica-se que as referências aos aspectos positivos têm quase a mesma freqüência que aos aspectos negativos. O que chama a atenção quanto aos aspectos negativos é a alusão de que a clientela "necessita de maior esclarecimento" e de que a "demanda é excessiva". O problema de falta de esclarecimento pode ser atribuído ao fato de que historicamente as ações educativas preventivas em saúde estiveram muito ausentes no diaa-dia do trabalhador da saúde. Quanto à demanda excessiva, isto talvez aconteça devido

\begin{tabular}{|c|c|c|}
\hline \multirow[t]{2}{*}{ Problemas } & \multicolumn{2}{|c|}{ Freqüência } \\
\hline & enfermeiros & vacinadores \\
\hline \multicolumn{3}{|l|}{ aspectos negativos } \\
\hline A clientela é muito exigente & - & 14 \\
\hline Há muitos faltosos & 04 & 13 \\
\hline A clientela é desinformada & 06 & 11 \\
\hline A demanda é excessiva & 05 & 09 \\
\hline Não aceitam a regionalização & 01 & 07 \\
\hline Não valorizam a atividade & - & 04 \\
\hline Reclamam do horário & 01 & 04 \\
\hline Perdem o cartão de vacinas & 01 & 03 \\
\hline \multicolumn{3}{|l|}{ aspectos positivos } \\
\hline Sem problemas com a clientela & 05 & 05 \\
\hline Clientela bem orientada & 04 & - \\
\hline Valorizam a atividade & 02 & 07 \\
\hline Segue as orientações & 02 & - \\
\hline Atende às convocações & 02 & - \\
\hline
\end{tabular}

ao horário de atendimento restringir-se aos dias úteis e apenas no horário comercial. Com relação aos faltosos, apenas três enfermeiros referiram que tentam localizar os faltosos quando de sua vinda aos outros setores da própria Unidade para outros atendimentos. Esta é mais uma evidência da desarticulação desta atividade com os demais setores da Unidade, principalmente com o Programa de Saúde da Criança.

- Visão dos responsáveis pela Vacinação nos níveis estadual regional e municipal central sobre o processo de municipalização do setor

Para complementar os dados coletados nos levantamentos, buscou-se identificar, através das entrevistas, a visão dos responsáveis sobre o processo de municipalização da vacinação. As falas foram analisadas através das seguintes categorias empíricas: operacionalização da vacinação; articulação entre os níveis estadual regional e municipal central; articulação entre o nível municipal central eo nível local e recursos humanos.

Neste trabalho são trazidas algumas falas dos entrevistados para ilustrar os itens discutidos.

\section{Operacionalização das ações de vacinação}

Na visão dos responsáveis no nível municipal, são apontados aspectos positivos como resultado da municipalização da vacinação, que são: comando único municipal e centralização do recebimento e distribuição dos imunobiológicos e insumos, o que permite uso mais ra- 
cional destes materiais, e melhor controle da rede de frio. Outro ponto positivo foi que o Estado continuou com a competência de fornecer estes materiais, bem como estabelecer toda retaguarda em relação às normas. Um dos entrevistados relata:

“A gente achou importante que além da coordenação das atividades de vacina, que tivesse também uma centralização do recebimento e distribuição das vacinas... isto diminui as falhas; ...você tem um poder maior de remanejar vacina ...tem condições de melhor acompanhar a conservação da vacina e eu acho que isso melhorou ...em relação à normas a gente tem tido toda retaguarda..." (Enfa municipal, atualmente)

Como limitador, ambos os níveis apontam a falta de uma rotina de supervisão: o Estado não supervisiona o Município e este não supervisiona de maneira sistemática suas Unidades. O nível municipal aponta também como limitador o horário de funcionamento das salas de vacinas e tem sugerido que este seja ampliado, no mínimo, durante todo o horário de funcionamento da Unidade.

A rticulação entre os níveis estadual regional e municipal central

A municipalização da saú de trouxe certo desconforto no relacionamento entre estes dois níveis. Foi traumática, principalmente para os recursos humanos, os quais foram municipalizados compulsoriamente. Além disso, houve troca de competência para supervisionar diretamente as ações de vacinação:

"Foi difícil a passagem de responsabilidades dos Centros de Saúde estaduais; o ERSA, que até então tinha também a obrigação de fazer supervisão, depois não pode fazer... foi proibido... foi um trauma muito grande... principalmente para os funcionários que estavam sendo municipalizados... eles se encontravam marginalizados pelo processo de municipalização... . Eu acho que até hoje ainda ocorrem problemas em alguns municípios que incorporaram o serviço mas não o recurso humano". (Enfạ estadual, 1987)

“No início os Centros de Saúde estaduais continuaram responsáveis pela vacinação; o município tentando chegar e o estado tentando segurar". (Enfa municipal, 1987)

Atualmente, a troca de informações entre os dois níveis é recíproca e corre sem maiores problemas; percebe-se que há um canal aberto para esta comunicação.
Articulação entre o nível municipal central e o nível local

Uma mel hor sistematização das ações do programa de vacinação no município foi possível a partir da criação do Grupo de Vigilância Epidemiológica Municipal - GVEM, em 1989; isto possibilitou uma melhor estruturação do grupo, principalmente a partir da Epidemia de Dengue que aconteceu neste município entre 1990 e 1991.

"A dificuldade nossa foi num crescente ...todas as ações de vigilância epi demiológica e de vacina ção não eram reconhecidas como uma coisa importante ...começou realmente a ganhar mais peso quando começou a epidemia de dengue. Ficou muito mais fácil que nós fossemos ouvidos ...". (Médica sanitarista da VE do Município, atualmente).

No momento (junho de 1993), a Vigilância Epidemiológica participa das decisões que envolvem o controle das doenças e o programa de vacinação, colaborando sobremaneira quando da abertura de novas salas de vacinação.

\section{Recursos humanos}

Desde 1983, a SMS se preocupava em preparar, nos aspectos teóricos e práticos, os recursos humanos que iriam assumir a vacinação, antes de abrir as novas salas, com a assessoria do Estado. Tal assessoria foi fundamental nesta fase, no tocante à montagem das novas salas:

“o município ia junto com o estado para aprender, tendo em vista a larga experiência que o estado tinha". (Enfa municipal, atualmente).

No entanto, também neste aspecto, o Município teve algumas dificuldades em certo período, porque a SMS não entendia que era necessário ter um funcionário o tempo todo na sala de vacina e nem permitia seu afastamento das atividades de rotina, para treinamentos:

“ ...essa era uma dificuldade ....a gente precisava de funcionário na sala de vacinas e nem sempre isto era considerado importante não era fácil tirar funcionário de Unidade para treinamento". (M édica sanitarista da VE do município, atualmente)

Atualmente, os recursos humanos são preparados previamente, porém os treinamentos estão centralizados no GVEM, fazendo com que o enfermeiro da Unidade nem sempre se envolva com esta atividade, o que tem dificultado a supervisão, pelo enfermeiro, dos vacinadores. Acredita-se que estes treinamentos poderiam ser realizados pelos enfermeiros do nível local, desde que fossem também prepara- 
dos para esta atividade. Isto, além de facilitar a supervisão, permitiria maior autonomia do nível local, que é onde se dá, de fato, a assistência à saúde da população.

\section{Conclusões}

No presente estudo, verificou-se que, desde a implantação das Ações Integradas de Saúde, houve um aumento numérico dos serviços de vacinação. Em 1983, havia em Ribeirão Preto 14 salas de vacinas e, em 1993, existiam 22, tendo havido um incremento de $57 \%$ na oferta destes serviços. Esta expansão ocorreu nos bairros periféricos e acredita-se que isto tenha possibilitado maior acesso da população ao benefício da vacinação. A municipalização da vacinação permitiu que houvesse uma centralização das decisões no nível municipal, trazendo consigo aspectos positivos, como: controle e avaliação contínua do PNI através de comando único municipal; racionalização do uso dos imunobiológicos e insumos disponíveis; melhora no controle da rede de frio no nível municipal. A criação do Grupo de Vigilância Epidemiológica

\section{Referências}

ALMEIDA, M. C. P. de; GOMES, D. L. S. \& SILVA, E., 1980. Avaliação da técnica de injeção intramuscular através do "Chek-list". Revista Brasileira de Enfermagem, 33:428-42.

BEGOSSI, M. R., 1984. Aspectos Técnicos e Científicos Inerentes à Injeção IM : a Vacinação Tríplice Como Oportunidade de Ampliação desses Conhecimentos. Tese de Mestrado, Rio de Janeiro: Centro de Ciências Biológicas e da Saúde, Universidade Federal do Rio de Janeiro.

BRASIL (Leis e Decretos), 1975. Lei no 6.259 de 30 de outubro.

BRASIL, 1988. Constituição da República Federativa do Brasil. Título VIII. cap.II. Seção II. Brasília.

BRASIL (Leis e Decretos), 1990. Lei no 8.080 de 19 de setembro.

CHRISTENSEN, P. D. \& KARLQVIST, S., 1990. Impacto de los promotores de salud en una zona de barrios pobres de Pucallpa. Boletin dela Oficina Sanitária Panamericana, 109:134-44.

COSTA, J. \& ALMEIDA, M. C. P. de, 1980. Orientações sobre a vacinação infantil no momento de sua aplicação. Revista Brasileira de Enfermagem, 33:393403.

ETIENNE, C., 1990. Desarrollo de los SILOS en Dominica y la cobertura de vacunación. Boletin de la Oficina Sanitária Panamericana, 109:547-51.

FOSTER, A. C., 1979. Cobertura dos Serviços de Imunização de Ri bei rão Preto Através de Entrevistas Domiciliares. Tese de Mestrado, Ribeirão Preto: Faculdade de Medicina, Universidade de São Paulo.

MPAS (Ministério da Previdência e Assistência Social),
Municipal permitiu uma melhor sistematização das ações de saúde coletiva, entre elas a vacinação. Isto possibilitou a formação, no nível municipal, de uma equipe que coordena estas atividades, inclusive sugerindo a implementação de estratégias que poderão colocar a vacinação como uma das prioridades, não apenas no nível municipal central, mas principalmente nas Unidades Básicas de Saúde.

No entanto, faz-se necessário apontar alguns aspectos negativos ainda presentes.

A centralização das decisões a nível central municipal e distrital, no tocante à vacinação, pode estar colaborando para a falta de envolvimento com esta atividade, por parte da equipe de algumas Unidades. Da mesma maneira, a centralização do treinamento e capacitação dos vacinadores e enfermeiros no nível municipal central tem também limitado a autonomia da enfermeira e da equi pe da própria UBS no tocante à supervisão e decisões relativas à vacinação. A falta de articulação das atividades dentro das Unidades de Saúde está fazendo com que a vacinação seja vista como algo de fora da Unidade.
1982. Reorientação da Assistência à Saúde no Âmbito da Previdência Social. Brasília: Centro de Documentação.

MS (Ministério da saúde), 1984. Manual deVacinação. Brasília: Centro de Documentação.

MS (Ministério da Saúde), 1985. Ações Integradas de Saúde. Brasília. 29 pp. (mimeo.)

MS (Ministério da Saúde), 1987. Conferência Nacional de Saúde, 8a. Brasília. 1986. Anais da 8a Conferência Nacional de Saúde. Centro de Documentação do Ministério da Saúde. 430 pp.

OMS (Organizacion Mundial de la Salud), 1974. Actas Oficiales. no 217. 27a Asamblea Mundial de la Salud. Ginebra. 7 a 23 de mayo.

PINHATA, M. M. M., 1990. Influência da Época deAplicação da Vacina BCG-ID em Crianças Com eSem Retardo do Crescimento Intra-Uterino Na Hipersensibilidade Tuberculínica Pós-vacinal. Tese de Doutorado, Ribeirão Preto: Faculdade de Medicina, Universidade de São Paulo.

RIBEIRÃO PRETO (Prefeitura Municipal), 1984. Lei no 4476 de 26 de abril.

RIBEIRÃO PRETO (Secretaria Municipal de Saúde), 1987. Lei no 5194 de 27 de novembro.

SÃO PAULO (Secretaria Estadual da Saúde), 1989. Centro de Vigilância Epidemiológica “Prof. Alexandre Vranjac". Rotei ro para rel atório de inspeção para funcionamento de Posto de vacinação e supervisão de Postos Credenciados para vacinação. (mimeo.)

SOBRAL, S., 1978. Atuação da enfermeira em campanha de vacinação contra a paralisia infantil e o sarampo. Revista Brasileira de Enfermagem, 31:449-65. 